\section{FORMAÇÃO DO PROFESSOR INDÍGENA EM HUMAITÁ, SUL DO AMAZONAS}

Danielle Ivana Pereira dos Santos Maria do Carmo Marques Gobbi ${ }^{2}$ Mario Marcos Lopes

Resumo: Considerando os muitos desafios que enfrentam os povos indígenas para a progressiva qualificação de sua educação escolar, esse trabalho tem como objetivo reconhecer a importância do processo de formação dos professores índios no contexto da educação brasileira e identificar o perfil desses ingressantes do ensino superior. Para tanto, inicialmente realizouse uma pesquisa bibliográfica e posteriormente uma pesquisa exploratória por meio do levantamento de dados junto a Coordenação Acadêmica do Instituto de Educação, Agricultura e Ambiente (IEAA). Desse modo, observou-se que durante os 10 anos de existência ingressaram nesse polo 36 indígenas, sendo em sua maioria do gênero masculino e o curso de pedagogia o mais procurado. Além disso, pode-se considerar que o número de desistência foi baixo entre os ingressantes, representando uma conquista para os povos tradicionais. Entretanto, nota-se a ausência de uma proposta para a formação de professores indígenas em contexto intercultural que segundo os Referenciais para a Formação de Professores Indígenas deve ser construída com a coparticipação de índios e não-índios e de uma equipe de profissionais sensíveis às demandas políticas das comunidades e com experiência acumulada com o ensino e a formação de professores em situações de diversidade cultural.

Palavras-chave: Educação Escolar Indígena; Formação; Humaitá.

\footnotetext{
Mestranda em Ciências Ambientais pela Universidade Federal do Amazonas. Especialista em Docência na Educação Superior pelo Centro Universitário Barão de Mauá. Graduada em Engenharia Ambiental pela Universidade Federal do Amazonas.

Mestre em Educação. Docente do Centro Universitário Barão de Mauá.

${ }^{3}$ Mestre em Desenvolvimento Regional e Meio Ambiente. Docente do Centro Universitário Barão de Mauá.
} Professor Coordenador na Rede Estadual de Ensino de São Paulo (Ribeirão Preto)
Abstract: Considering the many challenges faced by indigenous peoples for the progressive qualification of their school education, this work aims to recognize the importance of the process of training Indian teachers in the context of Brazilian education and to identify the profile of these higher education students. For this, initially a bibliographic research was carried out and an exploratory research was carried out by means of data collection with the Academic Coordination of the Institute of Education, Agriculture and Environment (IEAA). In this way, it was observed that during the 10 years of existence, 36 indigenous people joined this pole, being mostly male and the pedagogy course the most sought. In addition, it can be considered that the number of withdrawals was low among the tickets, representing an achievement for the traditional peoples. However, we note the absence of a proposal for the training of indigenous teachers in an intercultural context that according to the References for the Training of Indigenous teachers must be built with the participation of Indians and non-Indians and a team of professionals sensitive to the demands community policies and with accumulated experience with the teaching and training of teachers in situations of cultural diversity.

\section{Keywords: Indigenous School Education; Formation; Humaitá}

\section{Introdução}

As discussões acerca da educação escolar indígena no contexto da educação brasileira, nas últimas décadas, têm provocado reflexões em torno da legitimidade das lutas dos povos indígenas para garantia de seus direitos enquanto cidadãos brasileiros. Nessas trajetórias, encontra-se um cenário marcado por lutas históricas, fortalecimento das práticas escolares nas escolas indígenas e uma relação bastante íntima entre educação e cultura.

A partir da Constituição Federal de 1988, os índios brasileiros adquiriram o direito de serem considerados índios possuidores de uma língua, cultura e tradições próprias. Assegurou-se aos índios o direito de frequentar uma escola para a sua afirmação étnica e cultural e ser um dos principais veículos de assimilação e integração. É importante destacar que a promulgação das outras leis referentes à Educação Nacional, como o Plano Nacional de Educação e a Lei de Diretrizes e Bases da Educação (LDB) abordam os direitos dos indígenas a uma educação diferenciada, fundamentada na diversidade da língua, na valorização dos saberes milenares desse povo e 
na formação docente dos índios para atuarem em suas comunidades.

Sabe-se que a proposta de uma escola indígena de qualidade específica, só será possível se os próprios índios estiverem à frente do processo como professores e gestores da prática escolar, recebendo uma formação por meio de práticas inovadoras com o objetivo de torná-los capazes de atuar de uma forma crítica, consciente e responsável, de acordo com o contexto nos quais a s escolas estão inseridas (BRASIL, 2002)

Dessa forma, o professor indígena torna-se responsável pela interlocução da comunidade de sua aldeia com os representantes políticos e mediador dos elementos culturais, econômicos e científicos originários dessa relação, em conhecimento sistematizado para a escola intercultural.

Na verdade, nos últimos anos houve importantes avanços no tocante à educação para o índio e formação de professores indígenas. Corroborando com essa afirmação os Referenciais para a formação de professores indígenas (BRASIL, 2002, p.10) aponta que:

Nos últimos anos, a implantação de escolas em terras indígenas deixou de ser uma imposição da sociedade nacional e tornou-se uma reivindicação indígena a fim de se construírem novas formas de relacionamento com os demais segmentos da sociedade brasileira. Essa reivindicação não se traduz por qualquer tipo de escola, mas por um projeto definido de acesso a determinados conhecimentos acumulados pela humanidade e de valorização, pesquisa, registro e sistematização de práticas e saberes tradicionais. Para tal, o envolvimento da comunidade e o uso das línguas indígenas e do português, de metodologias adequadas aos processos próprios de ensino e aprendizagem, de calendários diferenciados e de materiais didáticos específicos constituem elementos essenciais a uma nova prática escolar.

Neste sentido o estado do Amazonas, por exemplo, detém várias etnias indígenas como as tribos Tenharim, Pirahã e Jiahui. Estas tribos são as que mais têm contato com a cultura do "homem branco", uma vez que deixam suas tribos e migram para a cidade de Humaitá situada no Sul do Amazonas. Acredita-se que a busca pela qualidade de vida seja o principal motivo desses indivíduos, cujos objetivos são a busca por emprego e ingresso nas universidades.

A Universidade Federal do Amazonas, campus Humaitá, possui seis cursos: Agronomia, Engenharia Ambiental, Pedagogia, Licenciatura dupla em Ciências: Matemática e Física; Ciências - Biologia e Química e em Letras - Língua Portuguesa e Língua Inglesa, nos quais verifica-se a presença de discentes indígenas e apesar do Amazonas ter sido pioneiro em diversas discussões sobre a formação de professores indígenas, ainda é recorrente a evasão e exclusão dos discentes e professores indígenas.

Por outro lado, diversas etnias já foram atendidas com a formação de seus professores no nível médio e também no nível superior. Porém, sabese que há um grande desafio, pois estamos cientes da quantidade de povos indígenas presentes no estado do Amazonas e que a demanda pela formação é constante e urgente.

Neste contexto, a pesquisa teve como objetivos:

- Realizar levantamento bibliográfico acerca do processo de formação do professor indígena;

- Destacar os desafios e avanços no processo de formação docente em Humaitá, na região sul do Amazonas;

- Identificar o perfil dos ingressantes e egressos da Universidade;

- Reconhecer o papel do professor indígena em Humaitá, região Sul do Amazonas.

Trata-se de uma pesquisa qualitativa, bibliográfica e exploratória, que a partir da literatura científica e dos dados secundários levantados junto a Coordenação Acadêmica do Instituto de Educação, Agricultura e Ambientes da Universidade Federal do Amazonas-Humaitá busca discutir, analisar e apontar caminhos diante da problemática apresentada.

\section{Revisão da Literatura}

\section{Formação de professores indígenas}

A ideia de formação e sua importância é vista como essencial ao crescimento profissional, seja para professores indígenas ou não. Estes profissionais da educação anseiam contribuir com o ensino de suas comunidades tendo em vista melhores condições de trabalho e educação.

\section{Breve histórico da educação indígena}

A educação escolar indígena no Brasil tem uma longa trajetória, tecida desde os primórdios da colonização e cujo modelo predominante, alheio às cosmologias indígenas, foi imposto com o explícito intuito colonizador, 
integracionista e civilizador. De acordo com estudos recentes que tratam da história da educação escolar indígena, podemos identificar quatro fases distintas dessa modalidade de escola na história da educação no Brasil (BERGAMASCHI, 2010a).

Primeiramente, no período colonial, a educação indígena era predominantemente de responsabilidade dos jesuítas, mas houve também as contribuições dos franciscanos, carmelitas, beneditinos e outros missionários. Esse processo denominado escolarização era apenas uma catequese, a fim de evangelizar ou cristianizar o índio. Seu real objetivo era pacificar e conseguir a mão de obra dos índios de forma escravizada para iniciar os trabalhos pela coroa portuguesa (NOGUEIRA, 2015).

Segundo Viveiros de Castro (2002, p.245 apud BERGAMASCHI, 2010, p. 57):

O "plano civilizador", dirigido aos indígenas e explicitado por Nóbrega em 1558 , visava "defender-lhe comer carne humana e guerrear sem licença do governador"; "fazer-lhes ter uma só mulher"; "vestirem-se"; "tirar-lhes os feiticeiros"; fazê-los viver quietos sem se mudar para outra parte ... tendo terras repartidas que lhes bastem". Com pequenas diferenças nos distintos tempos e espaços do Brasil colônia, esses princípios se mantiveram nos séculos de colonização, reforçados pela atuação de outras ordens religiosas como os beneditinos, franciscanos, carmelitas, lassalistas e salesianos, e retomados pelo Estado brasileiro no início do século XX, quando se 16 configura um segundo momento da educação escolar indígena.

A segunda fase nesse processo foi a criação do Serviço de Proteção ao Índio (SPI) em 1910. O principal foco desse serviço era uma política indigenista de integração à sociedade nacional, por isso foi enfatizado o trabalho agrícola e doméstico que submetia os índios a uma forma de semiescravidão. Em relação à educação o SPI tinha a proposta de valorizar a diversidade linguística e cultural dos indígenas, mas isso não aconteceu, pois não existiam especialistas para trabalhar a questão da língua materna. Por essa razão, seria inviável o ensino bilíngue, portanto estes objetivos ficaram apenas enraizados no discurso, pois na realidade a educação ofertada aos índios não levou em consideração os costumes, organização social e processos próprios de educar dos indígenas (MENDONÇA, 2016).

Segundo Mendonça (2016), na terceira fase o SPI é extinto e criada a Fundação Nacional do Índio (FUNAI) em 1967. Esse órgão traz ainda características de uma política integracionista, uma vez que buscava a pacificação dos índios a favor de grandes empreiteiras de exploração das riquezas naturais, o que não se diferenciou muito da primeira fase, porém começam a preparar os indígenas para atuarem na educação que era ofertada a eles. Além disso, a FUNAI estabeleceu o ensino bilíngue como forma de valorizar a cultura do povo.

De acordo com Brito Silva et al. (2011), a Lei 6.001 de 19 de dezembro de 1973 (Estatuto do Índio) reafirma a proposta da FUNAI sobre a valorização da língua materna, que assegura em seu artigo $1^{\circ}$, a regulação de sua situação jurídica e de suas comunidades com a finalidade de preservar sua cultura e integrá-los à comunidade nacional (BRASIL, 1973).

A partir daí desencadeia-se um movimento forte de afirmação da educação escolar indígena, por meio de leis, de criação de setores específicos para a gestão de escola e do envolvimento de lideranças e professores indígenas na condução desse processo, caracterizando uma nova fase da educação indígena no Brasil. Além disso, pode-se observar que as políticas educacionais voltadas para a educação indígena têm sua expressão na Constituição Federativa do Brasil de 1988 que, especificamente, no Capítulo III, artigo 210 assegura aos índios a formação básica comum e o respeito aos seus valores culturais e artísticos.

Com efeito a LDB de 1996, assegura às comunidades indígenas, o direito à educação escolar, com o objetivo de fortalecer as práticas culturais e os processos próprios de aprendizagem. Estabelece, ainda, a articulação dos sistemas de ensino para a oferta da educação escolar bilíngue e intercultural aos povos indígenas, de modo que lhes propiciar a recuperação de suas memórias históricas, a reafirmação de suas identidades étnicas, a valorização de suas línguas e ciências e o acesso às informações e aos conhecimentos técnicos e científicos da sociedade nacional e demais sociedades indígenas e não-índias (artigos 78 e 79) (BRASIL, 2002).

\section{Formação de professores indígenas no Amazonas}

A discussão da formação de professores indígenas no Estado do Amazonas começou a ser viabilizada desde 1988, pelo Movimento dos Professores Indígenas da Amazônia - atual COPIAM.

Os encontros tiveram início a partir do momento em que alguns professores indígenas, da etnia Tikuna, decidiram reunir-se e reivindicar 
o direito e o reconhecimento de serem professores indígenas. Antes disso, eram identificados como professores rurais, recaindo sobre eles toda uma visão etnocêntrica que orientava a atividade de docência realizava no interior de suas comunidades, não levando em conta suas convicções e identidades culturais. (CAVALCANTE, 2003).

Segundo Cavalcante (2003) em 1988, aconteceu o $1^{\circ}$ Encontro de Professores Indígenas da Amazônia, do qual participaram 41 professores indígenas, de 14 povos de Roraima e do Amazonas. A partir do terceiro encontro, o movimento passou a ser denominado Comissão dos Professores Indígenas do Amazonas e Roraima (COPIAR). Em outubro de 1992 , professores do estado do Acre também se incorporaram ao movimento. Atualmente, esse movimento se consolida no COPIAM e se reconhece como entidade autônoma, independente, sem vínculos políticos e religiosos e sem fins lucrativos, representando o conjunto de profissionais indígenas da Amazônia que atuam na educação e em todos os níveis e modalidades de ensino.

Com isso a pressão dos povos indígenas no Estado do Amazonas para garantir o direito à uma educação fez o governo apresentar um projeto de formação de professores indígenas, o Piraywara criado no Governo de Amazonino Mendes ${ }^{4}$. Esse projeto consiste na atuação de formação de professores indígenas para atuarem em suas respectivas comunidades, seu diferencial é a prioridade da língua materna.

Com isso, a Universidade Federal do Amazonas - UFAM também proporciona oportunidades de formação de professores indígenas pelos programas de licenciatura indígena: processo seletivo de licenciatura indígena; Políticas Educacionais e Desenvolvimento Sustentável-PSLIND, que beneficiam alguns municípios e também o Programa de Apoio à Formação Superior e Licenciaturas Interculturais Indígenas (PROLIND), que já apresentaram algumas contribuições para as etnias: Mura, SateréMaué e Munduruku.

\section{Procedimento Metodológico}

Inicialmente realizou-se um levantamento bibliográfico buscando compreender o processo de formação do professor indígena, bem como os desafios e avanços no processo de formação docente em Humaitá, na região sul do Amazonas. Corroborando Fonseca (2002, p. 32) esclarece:

4Atual governador do Amazonas (2017 - em exercício) e também nos períodos (1987 a 1990) e (1995 a 2003).
A pesquisa bibliográfica é feita a partir do levantamento de referências teóricas já analisadas, e publicadas por meios escritos e eletrônicos, como livros, artigos científicos, páginas de web sites. [...] uma pesquisa bibliográfica, permite ao pesquisador conhecer o que já se estudou sobre o assunto.

Posteriormente, a pesquisa exploratória concentrou-se no levantamento de informações junto a Coordenação Acadêmica do Instituto de Educação, Agricultura e Ambiente da Universidade Federal do Amazonas no mês de agosto de 2017, por meio consulta aos cadastros dos alunos e da ata de colação de grau dos discente.

A partir das respostas obtidas, estabeleceram-se indagações a respeito da formação dos indígenas no ensino superior, bem como, o perfil dos ingressantes, preferência de cursos, o preconceito e falta de estrutura curricular e didática para atendimento específico dessa clientela.

\section{Resultados e Discussão}

Formação de professores indígenas em Humaitá Amazonas

Atualmente em Humaitá, região sul do Amazonas (Figura 1) a UFAM possui o Campus Universitário do Polo Vale do Madeira fundado em 25 de novembro de 2005, por meio da Resolução $n^{0}$ 023/2005/Conselho Universitário (CONSUNI). O Campus, sediado em Humaitá (AM), atende aos municípios de Apuí, Borba Manicoré e Novo Aripuanã. Posteriormente com a Resolução $n^{\circ}$ 028/2005/CONSUNI, também de 25 de novembro, foi criada a Unidade Acadêmica de Humaitá, depois passou a se chamar Instituto de Agricultura e Ambiente, pela Resolução nº 028/2006/CONSUNI. Em 2009, o nome do Instituto foi alterado para Educação, Agricultura e Ambiente (IEAA), por meio da Resolução $n^{\circ}$ 011, do Conselho de Administração (CONSAD).

O IEAA oferece 6 (seis) cursos: Agronomia, Engenharia Ambiental, Pedagogia, Licenciatura dupla em Letras - Língua Portuguesa e Língua Inglesa, Licenciatura dupla em Matemática e Física e Licenciatura dupla em Biologia e Química.

No município há várias etnias, no entanto, as mais expressivas são Tenharim, Pirahã e Jiahui. Embora seja oferecido cota para os indígenas em todos os cursos ofertados pelo IEAA, nenhum deles é bilíngue. 
Figura 1- Mapa de localização do município de Humaitá, Amazonas Brasil.

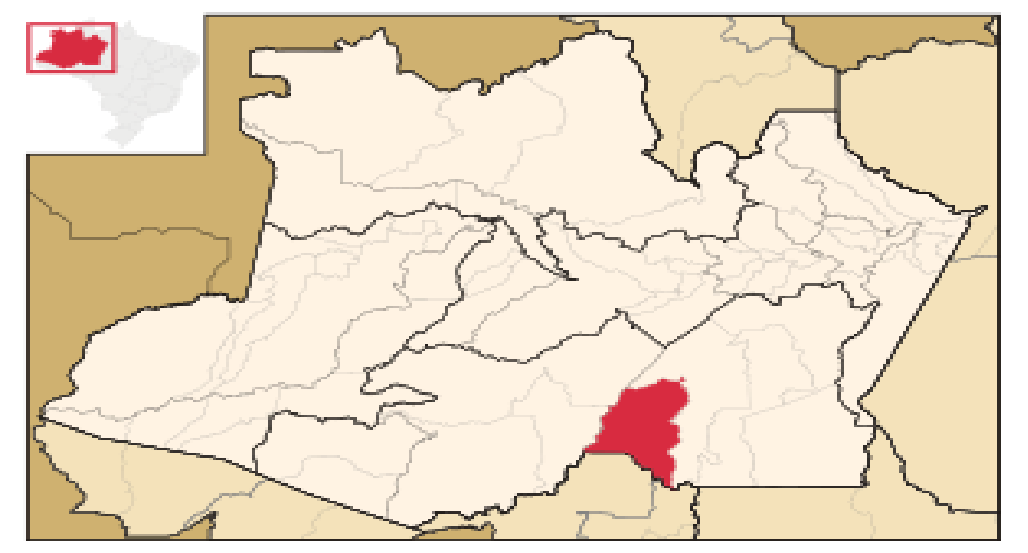

Fonte: https://pt.wikipedia.org/wiki/Humait\%C3\%A1_(Amazonas).

Quadro 1- Quantidade de indígenas e etnias que ingressaram no IEAA desde 2005 .

\begin{tabular}{|l|c|}
\hline \multicolumn{1}{|c|}{ Etnias } & $\mathbf{N}^{0}$ de ingressos \\
\hline Tenharim & 17 \\
\hline Pirahã & 8 \\
\hline Jiahui & 11 \\
\hline Total & 36 \\
\hline
\end{tabular}

Fonte: Arquivo acadêmico da Universidade do estado de Amazonas-Humaitá (2017).

Contudo, percebe-se que os indígenas que ingressaram nos diferentes cursos dominam o português e ainda preservam seu dialeto materno e reproduzem seus conhecimentos em suas comunidades.

Conforme pesquisa realizada junto a Coordenação Acadêmica do Instituto de Educação, Agricultura e Ambiente verificou-se que em seus 10 anos de funcionamento ingressaram nos cursos 36 indígenas, conforme disposto no Quadro 1.

De acordo com a Figura 2, pode-se observar que a preferência pelos ingressos indígenas foi na área de Humanas, com destaque para o curso de Pedagogia com $78 \%$ dos ingressos no IEAA, a procura possivelmente ocorreu, pois, esses profissionais almejam reproduzir os conhecimentos adquiridos na academia em suas comunidades, sobretudo, nos anos iniciais do ensino básico. Em contrapartida, nos cursos classificados na área das exatas houve pouca procura.

É importante destacar que as Diretrizes Curriculares Nacionais para o Curso de Pedagogia (BRASIL, 2006) levam em conta a necessidade de formar professores para atuar na educação com os diversos aspectos da diversidade, como na educação dos povos indígenas, na educação nos remanescentes de quilombos, na educação das relações étnico-raciais, na inclusão escolar e social das pessoas com necessidades especiais e dos meninos e meninas de rua.

A Figura 3, apresenta a distribuição dos ingressos indígenas por curso/ etnias. Neste sentido, corroborando com os resultados Amaral (2010) aponta que as áreas profissionais mais procuradas e incididas pelos indígenas são a educação (representando $46,6 \%$ do total) ao considerar os cursos por eles matriculados. Observa-se que as demais áreas profissionais também são fundamentais para o desenvolvimento das terras indígenas, vindo a instigar a possível criação de postos de trabalho nas aldeias e fora delas, os quais venham a absorver essa nova força de trabalho.

Ainda por meio da Figura 3, pode-se inferir que os discentes da etnia Tenharim foram os únicos que apresentaram preferência pelas exatas

Figura 2 - Distribuição dos ingressos indígenas por curso.

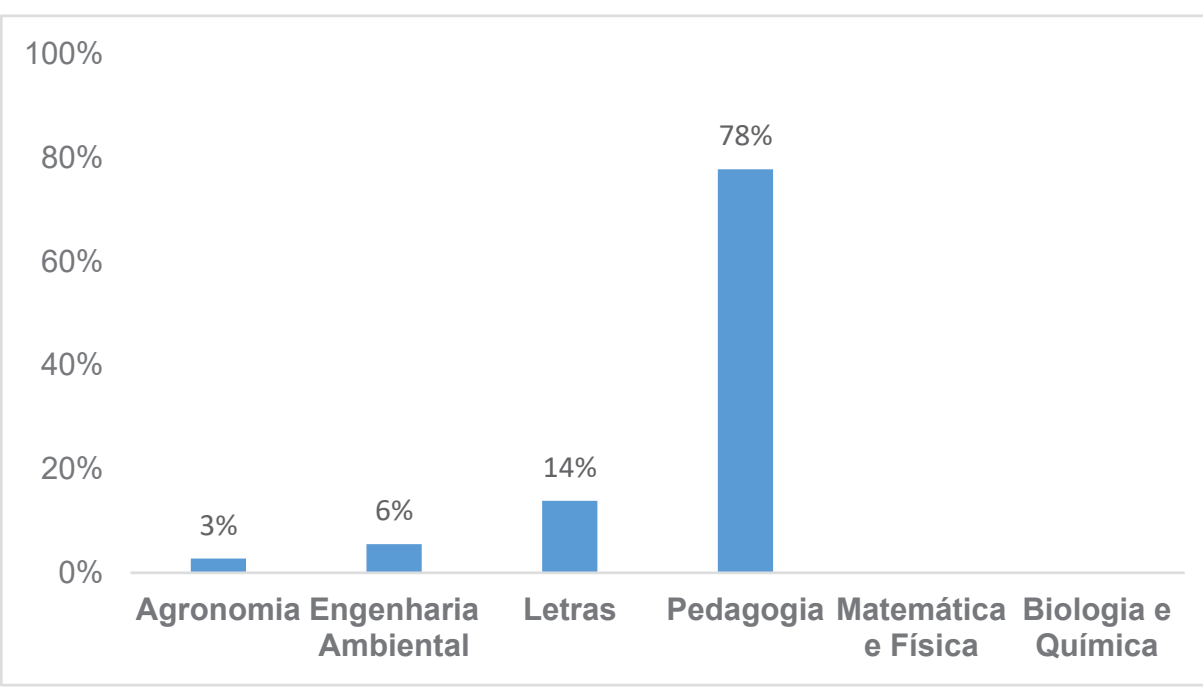


(Agronomia e Engenharia Ambiental), por outro lado, a etnia Jiahui em quase sua totalidade preferiram Pedagogia, esta opção talvez esteja relacionada com as constantes visitas e realização de projetos de extensão promovido pelo curso de Pedagogia - como a oficina de brinquedos desenvolvida junto às tribos desta etnia.

Ainda por meio da Figura 3, pode-se inferir que os discentes da etnia Tenharim foram os únicos que apresentaram preferência pelas exatas (Agronomia e Engenharia Ambiental), por outro lado, a etnia Jiahui em quase sua totalidade preferiram Pedagogia, esta opção talvez esteja relacionada com as constantes visitas e realização de projetos de extensão promovido pelo curso de Pedagogia - como a oficina de brinquedos desenvolvida junto às tribos desta etnia.

Observa-se também através da Figura 4 que o gênero masculino é predominante. Provavelmente deve-se ao fato de que muitas etnias, na tentativa de proteger as meninas contra os abusos e maus tratos, enviavam somente os meninos para estudar fora de suas aldeias por serem considerados "mais fortes", isso contribuiu para que as mulheres apresentem menor grau de escolaridade (NOGUEIRA, 2015).

Figura 3 - Distribuição dos ingressos indígenas por curso/etnias no IEAA.

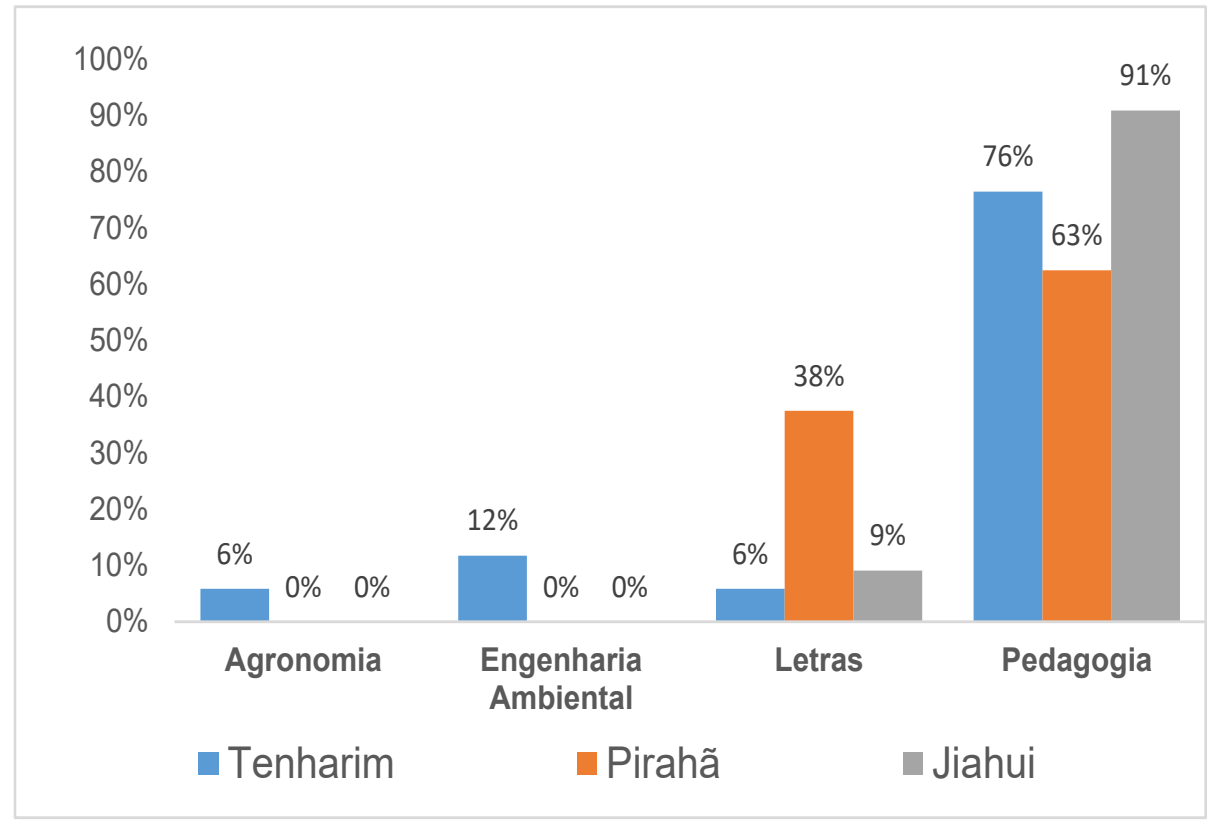

Figura 4 - Gênero dos ingressos das etnias no IEAA.

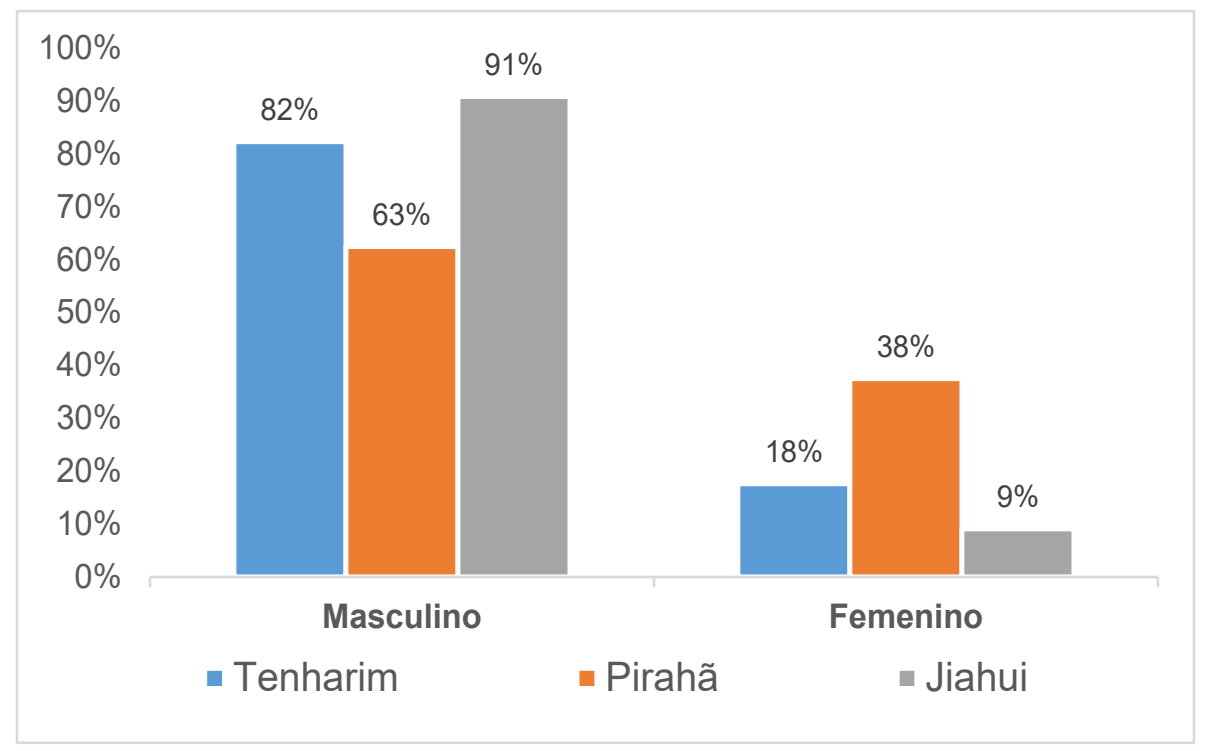

Figura 5 - Situação escolar dos ingressos por etnias no IEAA.

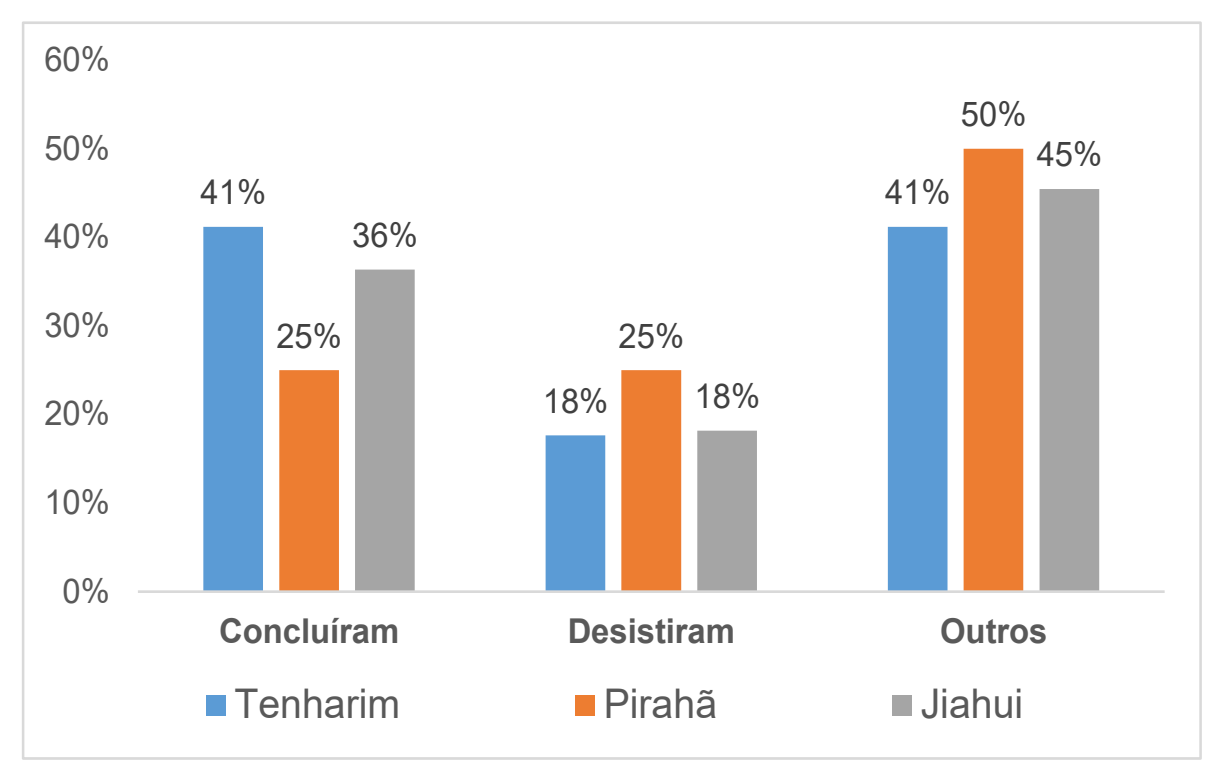

Do mais, Bergamaschi e Kurroschi (2013, p. 10) apontam que "a decisão de ingressar no ensino superior não é tarefa fácil para essas mulheres, pois, 
em consonância com sua cultura são preparadas para serem mães ainda muito jovens, isso se comparados aos nossos padrões atuais quando o assunto é a maternidade",

Posteriormente a pesquisa concentrou-se me quantificar o fluxo escolar dos indígenas ingressos no IEAA, analisando se o discente ingresso concluiu, desistiu, mudou de curso ou continua estudando. Desse modo, os resultados foram dispostos por meio da Figura 5.

Notou-se que a taxa de desistência foi baixa entre as etnias, o que representa uma conquista para o povo indígena ao qual pertencem, pois venceram os obstáculos do curso, para conseguir prosseguir ou concluir a graduação e continuar a luta por educação de qualidade e que respeite os costumes e tradições indígenas.

Angnes et al. (2014) apontam que a compreensão da permanência/ desistência do indígena no ensino superior é um processo social, que pode ser entendido como um "complexo fenômeno que envolve mudança não apenas de endereço (após cruzar a fronteira da aldeia), mas de toda uma série de contatos socioculturais do indivíduo, em todas as áreas da sua vida" (SARRIERA, 2005 apud ANGNES et al., 2014, p.203).

"No contexto atual, a sociedade nacional também tem o desafio de redefinir suas posturas, seus conceitos políticos e sociais, para garantir às minorias o direito à igualdade e à diferença" (ÂNGELO, 2006, p.214).

Expandindo as discussões, destaca-se também o preconceito dentro da universidade que como instituições tradicionalmente elitistas, não estavam, ou ainda não estão, preparadas para receber esses alunos, havendo necessidades de ações junto aos docentes e estudantes indígenas e não indígenas no enfrentamento das atitudes de discriminação, preconceito e desqualificação dos conhecimentos indígenas (BENDAZOLLI, 2008).

Corroborando a afirmação, Angnes et al. (2014) em sua pesquisa constatou que o "projeto de inclusão dos indígenas na universidade" restringe-se apenas ao acesso. Ou seja, o efeito psicossocial gerado pela ideia falsa que um programa suplementar de vagas indígenas gera na sociedade é inteiramente distorsivo, pois cria uma falsa noção de que a sociedade estaria tornando-se mais igualitária e justa, quando de fato o que acontece é um “alargamento do grau de aceitação e conformismo" (FREITAS, 2005, p. 68 apud ANGNES et al., 2014, p.204) para com as diferentes e sutis formas de injustiça e exploração da vida cotidiana.

De acordo com Bendazolli (2008), se fazem necessárias ações dentro da universidade para o enfrentamento dessas discriminações, que marcam a história e a sociedade.

Para Baines (2001), o preconceito constrói uma imagem altamente pejorativa, quanto ao índio, que o congela no tempo e no espaço, relegando-o ao atraso, à pobreza e à ignorância. Essas situações de preconceito tendem a ser mais forte principalmente com aqueles indígenas que não mudam seus costumes dentro da cidade, que falam a língua, comportam-se de forma diferente, tem vestimenta diferente, dentre outras características.

\section{Considerações Finais}

Embora, o estatuto do índio priorize o ensino em língua materna e os projetos pedagógicos, elaborados pelos órgãos oficiais, contemplem as necessidades indígenas, na prática o resultado dessa aplicação é insatisfatório, uma vez que esses órgãos não dispõem de um número de pessoas preparadas e comprometidas com a causa da educação indígena na região.

Por outro lado, percebe-se que apesar de todos os entraves encontrados pelos indígenas, em questões educacionais, eles estão conseguindo acesso à escola, inclusive ao ensino superior apesar de não ser bilíngue.

Um outro fato que também merece atenção é a ausência, nas comunidades indígenas, de membros da própria etnia com formação adequada para desenvolver satisfatoriamente uma educação de qualidade junto às suas aldeias, ou seja, há necessidade de se rever algumas questões no sentido de adequar propostas às realidades existentes na região pesquisada.

Observou-se ainda, que os índios do gênero masculino são em maior número nas três etnias, sendo o curso de Pedagogia o mais procurado. Além disso, pode-se considerar que o número de desistência foi baixo entre os ingressos, representando uma conquista para os povos indígenas, pois venceram os obstáculos do curso, para assim conclui-lo e continuar a "luta" pela qualidade da educação e da escola indígena.

Por fim, segundo os Referências para a Formação de Professores Indígenas (BRASIL, 2002, p.33) uma proposta para a formação de professores indígenas em contexto intercultural deve ser construída com a coparticipação de índios e não-índios, por meio de uma equipe de profissionais sensíveis às demandas políticas das comunidades e com experiência acumulada com o ensino e a formação de professores em situações de diversidade cultural. Tais profissionais, em razão da especificidade de sua formação, devem ser procurados e identificados com bastante cuidado não só no próprio estado, 
mas em outros, e integrados ao programa na qualidade de docentes dos cursos, participando na elaboração das propostas curriculares, na formulação dos materiais didáticos nas línguas maternas e em português junto com os professores indígenas e os demais docentes.

\section{Referências}

AMARAL, Wagner R. As trajetórias dos estudantes indígenas nas Universidades Estaduais do Paraná: sujeitos e pertencimentos. Tese (Doutorado em Educação) - Universidade Federal do Paraná. Curitiba, 2010.

ÂNGELO, Francisca Novatino P. de. A educação escolar indígena e a diversidade cultural no Brasil. In: BRASIL. Formação de professores indígenas: repensando trajetórias. Brasília: Ministério da Educação, Secretaria de Educação Continuada, Alfabetização e Diversidade, 2006. p.207-215.

ANGNES, J. S. et al. Permanência na universidade: o que dizem os estudantes indígenas da Universidade Estadual do Centro-Oeste do Paraná. HOLOS, ano 30, v. 6, p.190-205, 2014. Disponível em: $<$ http://www2.ifrn. edu.br/ojs/index.php/HOLOS/article/view/1658/pdf_136>. Acesso em: 17 nov. 2017

BAINES, Stephen G. As chamadas "aldeias urbanas" ou índios na cidade. Revista Brasil Indígena. Brasília, v.1, n.7, 2001.

BENDAZOLLI, Sirlene. Políticas de acesso ao ensino superior: o programa Diversidade na Universidade. Caderno de educação escolar indígena - PROESI. Barra do Bugres: UNEMAT, v. 6, n. 1, 2008.

BERGAMASCHI, Maria Aparecida. Educação escolar indígena no século XX. Currículo sem fronteiras, v.10, n.1, p.12-32, 2010a.

BERGAMASCHI, Maria Aparecida; KURROSCHI, Andreia Rosa da Silva. Estudantes indígenas no ensino superior: o programa de acesso e permanência na UFRGS. Políticas Educativas, Porto Alegre, v. 6, n.2, p. 1-20, 2013. Disponível em: < http://seer.ufrgs.br/index.php/Poled/article/
viewFile/45654/28834>. Acesso em: 17 nov. 2017.

BERGAMASCHI, Maria Aparecida; MEDEIROS, Juliana Schneider. História, memória e tradição na educação escolar indígena: o caso de uma escola Kaingang. Revista Brasileira de História. São Paulo, v. 30, p. 55 $75,2010 b$

BRASIL. Constituição da República Federativa do Brasil. Disponível em: www.senado.leg.br/atividade/const/con1988/CON1988 05.10.1988/ CON1988.asp.Acesso em julho de 2017.

BRASIL. Conselho Nacional de Educação. Resolução CNE/CP n⿳0 1, de 15 de maio de 2006. Institui Diretrizes Curriculares Nacionais para o Curso de Graduação em Pedagogia, licenciatura. Disponível em: http://portal.mec. gov.br/cne/arquivos/pdf/rcp01 06.pdf. Acesso em: 17 nov. 2017.

BRASIL. Formação de professores indígenas: repensando trajetórias. Brasília: Ministério da Educação, Secretaria de Educação Continuada, Alfabetização e Diversidade, 2006.

BRASIL. Lei no . 6.001 de 19 de dezembro de 1973. Dispõe sobre o Estatuto do Índio. Disponível em: http://www.planalto .gov.br/ccivil_03/leis/L6001. htm. Acesso em: 17 ago. 2017.

BRASIL. Lei nº 9394 de 20 de dezembro de 1996. Estabelece as Diretrizes e Bases da Educação Nacional. Disponível em: <http://portal.mec.gov.br/ arquivos/pdf/ldb.pdf $>$. Acesso em: 12 nov. 2017.

BRASIL. Secretaria de Educação Fundamental. Referências para a formação de professores indígenas. Brasília: MEC; SEF, 2002. Disponível em: <http://portal.mec.gov.br/seb/arquivos/pdf/Livro.pdf. Acesso em: 17 fev. 2017

BRITO SILVA, Cristiane Aparecida. Lutas e contradições enfrentadas pelos índios xavantes em busca da educação na cidade de Barra do Garças - MT. Revista Eletrônica da Univar, n. 6, p. 263-268, 2011. 
CAVALCANTE, Lucíola Inês Pessoa. Formação de professores na perspectiva do Movimento dos Professores Indígenas da Amazônia. Revista Brasileira de Educação, n.22, p. 15-22, jan./abr. 2003. Disponível em: $<$ http://www.scielo.br/pdf/rbedu/n22/n22a03.pdf > . Acesso em: 17 fev. 2017.

GERHARDT, Tatiana Engel; SILVEIRA, Denise Tolfo (Org.). Métodos de pesquisa. Porto Alegre: Editora da UFRGS, 2009.

LINHARES, Célia; GARCIA. Regina Leite; CORRÊA. Carlos Humberto Alves. Cotidiano e Formação de Professores. Brasília: Liber Livro, 2011.

MEDONÇA, Maria de Fátima dos Santos. Contribuições da licenciatura intercultural na perspectiva dos professores indígenas. 2016, $72 \mathrm{f}$. Monografia (Licenciatura em Pedagogia) - Universidade Federal do Amazonas.

NOGUEIRA, Eulina M. Leite. MENDONÇA, Maria de Fátima dos Santos. Formação de professores indígena no Amazonas: caso piraywara, 2015. Disponível em <http://www.enforsupunb2015.com.br/congresso/dvd/ comunicacaooral.php>. Acesso em: 27 set. 2017. 